\title{
Implications of Alternative Crop Insurance Subsidies
}

\author{
Aleksandre Maisashvili ${ }^{1 * \star(10), H e n r y ~ L . ~ B r y a n t ~}{ }^{2}$ and Jason P.H. Jones ${ }^{3}$ \\ ${ }^{1}$ Agricultural and Food Policy Center, Texas A\&M University, 2124 TAMU, College Station, TX, USA, ${ }^{2}$ Texas A\&M \\ University, 2124 TAMU, College Station, TX, USA and ${ }^{3}$ RTI International, 3040 Cornwallis Road, RTP, NC 27709, USA \\ ${ }^{*}$ Corresponding author. Email: amaisashvili@tamu.edu
}

\begin{abstract}
In this research, we analyze the economic effects across various crop insurance subsidy and policy scenarios to determine producer insurance choice response, total premium and subsidy payments and study their economic implications on dryland corn, soybean, and winter wheat producers. We rely on the expected utility maximization framework to rank policy combination sets that are available to a typical producer to analyze the impacts of crop insurance subsidy changes and elimination of certain insurance policies across the three crops. Several scenarios were analyzed across subsidy and policy options and were found to have noticeably different farmer behavioral responses and economic implications.
\end{abstract}

Keywords: Crop insurance; risk management; simulation

JEL Classifications: C15; Q10; Q12; Q18

\section{Introduction}

Crop insurance is of considerable importance to the U.S. agricultural sector and from a government spending perspective. In recent years, taxpayers have spent about $\$ 6$ billion per year on governmentprovided subsidies - more than half of the amount spent on premiums (USDA-RMA, 2018). Support for the crop insurance program from the agricultural industry is widespread, as demonstrated by a letter sent by the producer groups, agricultural finance organizations, insurance industry groups, and others urging U.S. lawmakers to make no significant changes as a part of a new farm bill (Letter to Congress, 2018).

Crop insurance subsidies are both a significant factor contributing to the success of crop insurance and a cause for concern for critics. For example, Wright (2014) argues that much of the federal spending, especially administrative and operating expenses, goes to insurance companies rather than to agricultural producers and that subsidies to farmers flow to those that earn more than nonfarm households. Further, approximately $68 \%$ of total crop insurance subsidies were paid to producers in the highest $10 \%$ of the crop sales distribution (Bekkerman, Belasco, and Smith, 2018). Bekkerman, Belasco, and Smith (2018) further stress that farms in the bottom $80 \%$ of crop sales receive about the same total amounts of agricultural risk coverage payments, price loss coverage payments, and crop insurance subsidies as farms in the top $2 \%$. This implies that placing more stringent restrictions on existing crop insurance subsidy rates would primarily affect the top fraction of farm businesses and result in significant taxpayer savings (Bekkerman, Belasco, and Smith, 2018). In addition, Goodwin and Smith (2013) emphasize that nonagricultural reinsurers could mitigate agricultural risks, and that the potential losses in agriculture are much smaller relative to the value of the nonagricultural risks that those companies insure.

Given that crop insurance subsidies have become such a large taxpayer expense, modification of the current subsidy structure might seem unavoidable. In particular, the Congressional Budget

(c) The Author(s) 2020. This is an Open Access article, distributed under the terms of the Creative Commons Attribution licence (https:// creativecommons.org/licenses/by/4.0/), which permits unrestricted re-use, distribution, and reproduction in any medium, provided the original work is properly cited. 
Office's (CBO) recent report anticipates around $\$ 21$ billion savings on subsidies from 2020 through 2028 (CBO, 2018). On March 11, 2019, the White House released the budget for FY 2020 that included numerous mandatory initiatives surrounding agricultural programs (White House, 2019). Among the proposed changes included modification to the crop insurance program. The budget proposed the elimination of crop insurance subsidies for farmers with adjusted gross incomes over $\$ 500,000$, as well as proposed reducing average insurance premium subsidies from 62 to $48 \%$ (White House, 2019). However, while the changes have been proposed, nothing has been officially legislated.

A change, modification, or elimination in premium subsidies would greatly impact producer choices. As a result, producers may change the type of insurance policy purchased, reduce their coverage level, modify the number of acres covered, or make no changes. However, producers are unlikely to entirely withdraw from crop insurance as it is often required by agricultural lenders as a condition to receive operating loans. For example, Ifft, Kuethe, and Morehart (2013) describe how agricultural lenders protect themselves from credit default risk through a variety of measures, and requiring crop insurance participation allows them to accept loan applications with less collateral. In addition to lending institution incentives, producers view crop insurance as an important tool to repay their loans, and the $\mathrm{CBO}$ projects that cutting federal subsidies for premiums would not substantially affect crop insurance participation rate (White House, 2019).

To the best of the authors' knowledge, research exploring producer insurance selection in response to changes in eligibility and subsidies has not been conducted. Yi, Bryant, and Richardson (2019) econometrically analyzed the demand for crop insurance, calculating various price elasticities of demand. The current work is distinguished from that previous effort in two important respects. First, this work uses 2018 data, whereas the previous work used the data centered around the year 2000. The present study will reflect the current policy and economic environment, and is, thus, more relevant to inferring the potential effects of shocks in the present day. Second, the previous study used an econometric approach, which inherently measures the effects of infinitesimal changes. This study uses an optimization approach that is suitable for analyzing the potential effects of qualitative and much more drastic changes that we wish to consider (e.g., the complete elimination of one type of policy, as it will be discussed later). This research will analyze the economic effects across various crop insurance subsidy and policy scenarios to determine producer insurance choice response, total premium and subsidy payments, and determine the economic implications on dryland corn, soybean, and winter wheat producers. The resulting decisions will impact their economic returns in the face of production variability, and affect the taxpayer cost to subsidize such programs.

\section{Background}

The Federal crop insurance program has grown tremendously over the last 20 years. Producers today rely more heavily on the crop insurance program than at any time in the past, as it has become the primary risk mitigation tool available to farmers. Participation in the crop insurance program was given a large boost with the passage of increased premium subsidies, included in the 2000 Agricultural Risk Protection Act (ARPA). In 2018 the program insured about $\$ 109$ billion in liabilities on 335 million acres nationwide, with total premiums reaching $\$ 10$ billion, of which over $\$ 6$ billion was paid in subsidies (USDA-RMA, 2018). In comparison, the program in 1994 insured only $\$ 13$ billion in liabilities, with total premiums and subsidies totaling $\$ 949$ million and $\$ 254$ million, respectively. The Agricultural Act of 2014 introduced shallow loss programs (i.e., Agricultural Risk Coverage), designed to help producers insure the losses that are smaller than those covered by most crop insurance policies, in some cases covering crop insurance deductibles. A key factor in the program's rise has been the introduction, and subsequent growth, of premium subsidies. Such subsidies provide producers a financial incentive to participate (O’Donoghue, 2014). 
As subsidy rates have increased, crop insurance has become cheaper for producers, and higher degrees of farmer participation and coverage levels have been observed.

Two major problems associated with crop insurance have been widely accepted in the literature: moral hazard and adverse selection (Glauber, 2004; Goodwin, 1993; Shaik et al., 2008). Moral hazard problems arise when insured producers alter their behavior after purchasing insurance to affect their likelihood of collecting an indemnity (Glauber, 2004). Adverse selection occurs when the producers have more information about the risk of loss than the insurer and are, thus, better able to determine the fairness of the premium rates (Harwood et al., 1999). To mitigate the moral hazard problem, crop insurance deductibles have been used that require a cash outlay before the benefits of the policy can be realized. To tackle adverse selection, policy makers have substantially increased subsidies to induce crop insurance participation by less risky producers (Shaik et al., 2008). Therefore, strong subsidy incentives have been provided to offset negative actuarial incentives for less risky producers. ${ }^{1}$

In addition to increasing subsidies and expansions of the crop insurance program, recent changes have modified the types of crop insurance products offered to producers. For example, in 1995, the program only permitted yield insurance. Today, farmers have flexibility in tailoring crop insurance coverage to best suit their needs. Most producers can choose insurance that covers their individual crop yield (Yield Protection [YP]), or insurance that covers their estimated market revenue (Revenue Protection [RP]). This is calculated based on their individual yield and a commodity futures price. Revenue policies allow the revenue guarantee to be improved by the price at harvest time, or with Harvest Price Exclusion, revenue can be based strictly on the price as of planting time (Revenue Protection with Harvest Price Exclusion [RP-HPE]). Producers can choose to have their individual production units covered individually (basic or optional unit structure), or collectively (enterprise unit structure). Finally, producers can select different coverage levels. In most cases, available coverage levels range from $50-85 \%$ in $5 \%$ increments. Indemnities are calculated based on the extent to which the realized yield or revenue falls below a threshold associated with the selected coverage level. That is, a lower coverage level corresponds to a higher deductible and greater extent of self-insurance.

Previous studies on the impacts of subsidy changes on crop insurance decision making are limited. Most of the studies focused on how changes in the price of premiums affect demand for crop insurance (Coble et al., 1996; Gardner and Kramer, 1986; Goodwin, 1993; Goodwin, Vandeveer, and Deal, 2004; Serra, Goodwin, and Featherstone, 2003; Shaik et al., 2008). Most of these works investigated activity before the implementation of ARPA. O'Donoghue (2014) and Babcock and Hart (2005) focus specifically on subsidy impacts. O'Donoghue (2014) analyzed the effects of changes in subsidies on producers' decisions to participate in crop insurance, following the enactment of ARPA in 2000, when newer premium subsidies were implemented. The research indicated that subsidies appeared to have a larger effect on the intensity of crop insurance use, suggesting that the subsidies' largest effects were to induce those already enrolled in crop insurance to participate in higher coverage levels. Babcock and Hart (2005) examined the effects of post-ARPA subsidy rates (as opposed to either premium levels or rates) on the level of enrollment for revenue and yield policies. The authors found that subsidies were influential in changing the decisions of the producers, especially with respect to the adoption of higher levels of coverage after the passage of ARPA. Both studies were based on county-level data, and the results showed overall changes, not focusing on how producers would react in the absence of certain insurance products or how producers would react to changes in the premium subsidies. Du, Hennessy, and Feng (2013) studied how natural resources affect insurance contract choice, assuming that crop insurance premiums are actuarially fair. Their work suggests that interaction between the crop insurance policy and the natural resources explains the reason why higher coverage levels are

\footnotetext{
${ }^{1}$ The term "less risky producers" refers to farmers operating in more productive regions, where the probability of indemnities being claimed is lower when compared to other areas.
} 
chosen in more productive areas. Du, Feng, and Hennessy (2016) examined the extent to which farmers' crop insurance choices were in line with economic theory. The authors constructed an expected utility maximization framework to explore the trade-offs between higher risk protection and large subsidy payments. Their research showed that assuming an actuarially fair premium, a rational decision maker should choose either the coverage level with the highest premium subsidy or a higher coverage level in general. The authors found that the probability of choosing an insurance product decreases as out of pocked expenditure increases. In this article, we explore how producers would participate in different coverage levels, within the same insurance plan, and how participants would switch from one plan into another, which to our knowledge has not been previously studied.

\section{Data}

We analyze the impacts of subsidy changes and the consequences of elimination of certain insurance programs for three dryland crops: corn, soybeans, and winter wheat. In 2018, corn, soybeans, and wheat made up roughly $63 \%$ of all acres enrolled in crop insurance (USDA-RMA, 2018).

To calculate premium rates for each state, county, crop, type, and practice (SCCTP) combination, we use the USDA Risk Management Agency's (RMA) official 2018 Actuarial Data Master $(\mathrm{ADM})$ and exact crop insurance premium calculation instructions according to the M-13 Handbook (USDA-RMA, 2019a). ${ }^{2}$ We use National Agricultural Statistics Service (NASS) county yield data as a starting point to determine production history for each SCCTP combination. NASS data are also used to calculate characteristics of the distribution of crop yields being insured (standard deviation, deviates from trend, etc.) for each SCCTP combination.

\section{Methodology}

\subsection{Ranking risky alternatives}

To analyze the impacts of crop insurance subsidy changes and elimination of certain insurance policies across our three crops, we rely on expected net returns (ENR) to rank policy combination sets that are available to a typical producer. Producers are free to choose from numerous possible combinations of crop insurance choices: policy type, coverage level, unit structure, and the trend adjustment option. Each combination will result in different expected total net returns, reflecting market receipts, crop insurance premiums, and indemnities. ${ }^{3}$ A policy combination, which results in the highest expected utility for a given scenario, will be assumed to be the most preferred insurance scheme by a producer. ENR for a given policy combination, $i$, can be written as:

Expected Net Returns $\left(E_{N} R_{i}\right)=$ market receipts + insurance indemnities in $_{i}$ premium cost $_{i}$,

where market receipts is the same for all insurance policy combinations, and is the product of harvest time crop price and realized yield. The market price is a simulated harvest time futures price observed at the time of planting. The realized yield is simulated from production history data using a normal distribution. ${ }^{4}$ The deterministic component is calculated as a trend forecasted

\footnotetext{
${ }^{2}$ We run the analysis only for nonirrigated practices for all three crops, including following and not following another crop in case of soybeans.

${ }^{3}$ The cost of production was not included in the ENR calculation due to the unavailability of such data. However, production costs can be reasonably assumed to not vary with the crop insurance coverage decision. Farmers are assumed to engage in multi-stage decision making, where they decide to plant a particular crop and then make crop insurance choices. Costs (other than premiums) are not expected to vary significantly with crop insurance decisions.

${ }^{4} \mathrm{We}$ acknowledge that assuming yields are normally distributed may bias the estimation procedures for some SCCTP. However, as Ramirez, Misra, and Field (2001, p. 3) state, consensus regarding the possible non-normality of crop yield distributions has not been reached in the agricultural economics literature. Moreover, Just and Weninger (1999) identified potential problems with previous studies that shed doubt on the validity of early findings of yield non-normality.
} 
yield, and the standard deviation is calculated from the residuals by regressing the past observed yields on a time trend. The harvest time price is simulated following a basic generalized Wiener process

$$
P_{t+1}=P t e^{\sigma \varepsilon \sqrt{\Delta t}}
$$

where $P_{t}$ is a harvest time futures price observed at the time of planting in period $t ; \sigma$ is the annualized standard deviation of a crop price obtained from past observations; and $\epsilon$ is a correlated standard normal deviate obtained by multiplying a factored covariance matrix between price and county yields by a vector of standard normal deviates. This specification for simulating harvest time prices is used by RMA in their process for determining premiums for revenue policies.

The producer premium calculations are briefly described in Section 4.2 and insurance indemnities for YP, RP, and RP-HPE are calculated following RMA's P21-1 and P21-2 handbooks (USDA-RMA 2019b, 2019c).

To rank risky alternatives, we assume that producers have a constant absolute risk aversion (CARA) coefficient and maximize their expected utility represented by a negative exponential utility function. We apply a two-period optimization problem, where certain premium costs are paid in the planting period, and uncertain indemnities and market receipts are realized in the harvest period. We assume that the producer maximizes the present value of expected utility across numerous possible combinations of crop insurance parameters (unit structure, policy type, and coverage level).

For a given policy combination, $i$, we write the present value of utility (PVU) as

$$
P V U_{i}=\left(1-e^{\lambda c_{i}}\right)+\frac{\left(1-e^{-\lambda w_{i}}\right)}{(1+r)^{\Delta t},}
$$

where $\lambda$ is a CARA coefficient, $c$ is a certain insurance premium cost, $w$ is a stochastic outcome of a risky prospect, which is the sum of market receipts and any indemnity, $r$ is a per annum discount rate, and $\Delta t$ is the length of time between planting and harvest measured in years.

The present value of expected utility (PVEU) for a given policy combination can be estimated by taking a simple average of $P V U$ across $L$ simulated trials:

$$
P V E U_{i}=\left(1-e^{\lambda c_{i}}\right)+\frac{1}{(1+r)^{\Delta t}} \times \frac{1}{L} \sum_{l=1}^{L}\left(1-e^{-\lambda w_{i, l}}\right)
$$

where $L$ is number of simulation trials, and $w_{i, l}$ is the sum of stochastic market receipts and stochastic indemnities for trial $l$. We specify $\Delta t=0.75$, which is approximately the time between insurance purchase and indemnities collection. We selected a discount rate $r$ of $6 \%$, in the range of typical operating loan rate and discount rate suggested by other researchers (Maisashvili, Bryant, and Richardson, 2016; Monge et al., 2014; Richardson et al., 2007; USDA-FSA, 2019).

Although CARA is not usually regarded as a desirable risk property, the convenience of this functional form has found extensive use in decision analysis (Hardaker, 2004). CARA allows for the coefficients of absolute risk aversion to be applied to consequences measured in terms of wealth or income (Anderson and Hardaker, 2003). Hardaker (2004) points out that there is a numerical problem in evaluating this function for large values of $w$ in association with relatively large values of $\lambda$. To account for this issue, we consulted Anderson and Dillon (1992), where they proposed a scale for classifying the degree of risk aversion, which is based on the magnitude of the relative risk aversion coefficient. Their proposed values of relative risk aversion range from 0.0 to 4.0, where 0.0 represents a risk neutral individual, and 4.0 represents an extremely risk averse agent. Given that

$$
\lambda=\frac{R_{r}(w)}{w_{0},}
$$


where $R_{r}(w)$ refers to a relative risk aversion coefficient, the range of $\lambda$ can be represented by

$$
\lambda=\left[0, \frac{4.0}{w_{0}}\right],
$$

where $w_{0}$ is the initial wealth of a producer. Therefore, the values of $\lambda$ are small when initial wealth is relatively large, as suggested by Hardaker (2004). This implies a producer's risk aversion decreases as wealth increases. The policy combination yielding the highest PVEU will be considered as the most preferred alternative for a given scenario.

Considering data are unavailable for producer's initial wealth $\left(w_{0}\right)$, we consulted USDA's Agricultural Resource Management Survey (ARMS) Farm Financial and Crop Practices data and looked at their reported income statements and balance sheets for years 2015-2018 (USDA-ARMS, 2018). ARMS does not provide initial net worth in the financial statements; however, they report farm equity values. By looking at their reported data, the value of farm equity are between 3.8 to 5.2 times higher than the crop value (the product of reference yield, the insured price, and number of acres). Therefore, to draw a random wealth parameter for a hypothetical farmer for a given SCCTP combination, we used a uniform distribution. ${ }^{5}$ In addition, we assumed that a typical farmer is moderately risk averse and selected a relative risk aversion coefficient to be $2.5 .^{6}$ Therefore, absolute risk aversion coefficient, $\lambda$, was estimated as follows:

$$
\lambda=\frac{2.5}{\widetilde{w p} \times \text { projected price } \times \text { reference yield } \times \text { number of insured acres }}
$$

where $\widetilde{w p}$ is a stochastic wealth parameter and is distributed as:

$$
\widetilde{w p} \sim \text { uniform }[3.8,5.2]
$$

\subsection{Premium rate calculations}

In addition to market receipts and crop insurance indemnity calculations, producer premiums are also needed to generate ENR for a given SCCTP combination. The producer premium was generated as follows. The base rate at the $65 \%$ coverage level charged for a COMBO crop insurance policy is given by

$$
\text { Base Rate }=\left(\frac{Y_{\text {rate }}}{Y_{\text {ref }}}\right)^{E} \times \text { Reference Rate }+ \text { Fixed Rate, }
$$

where $Y_{\text {ref }}$ is the county reference yield, and all variables on the right-hand side are retrieved from the RMA's ADM, except for the producer's rate yield, $Y_{\text {rate }}{ }^{7}$ This base rate is the premium per dollar of liability for YP at the $65 \%$ coverage level for an optional unit structure. The $Y_{\text {rate }}$ is specific for each production unit, while the other values in this calculation are set for a county for each crop. Premiums for RP, RP-HPE, alternative coverage levels, enterprise unit structures, and other optional policy features are all calculated by making adjustments to this base rate. The normalized liability for a coverage level $\mathrm{cl}$ is

$$
\text { Liability }=Y_{a p p r} \times c l
$$

\footnotetext{
${ }^{5} \mathrm{We}$ also simulated the wealth parameter with a normal distribution, and the difference between the two distributions is negligible.

${ }^{6}$ The results were also estimated for nearly risk neutral and extremely risk averse individuals by selecting $R_{r}(w)$ values of 0.01 and 4.0, respectively, and the results are presented in tables A1 and A2 in the Appendix.

${ }^{7}$ Beginning the 2011 crop year, the RMA took an initiative to combine and simplify crop insurance, where YP and RP insurance policies were combined into one general policy, commonly known as COMBO.
} 
where $Y_{a p p r}$ is the producer's approved yield and $c l$ is written as a proportion (e.g., 0.75 representing a $75 \%$ coverage level). The liability is an integral part for calculating the total premium, $T P_{c l, u}$ for a unit structure $u .{ }^{8}$ Finally, the producer premium, $P P_{c l, u}$, calculated from total premium as net of subsidy is given by

$$
P P_{c l, u}=T P_{c l, u} \times\left(1-\text { subsidy } \text { percent }_{c l, u}\right)
$$

\subsection{Correlation induction for simulated yield histories}

As mentioned, one of the main components for calculating the producer premiums is the producer's rate yield, $Y_{\text {rate }}$. NASS provides time-series weighted average county yield level data for all SCCTP combinations. Thus, to analyze the impacts of subsidy or policy changes on crop insurance decisions, farm-level yield data are a primary factor for the analysis. However, farm-level yield data are sparse, not broadly representative, and frequently suffer from selection bias (Gerlt, Thompson, and Miller, 2014).

To create representative farm-level yield data from a county-level yield time-series, and generate a production history for each of $n$ individual farmers, we employ a standard correlation induction method. The process below describes generating an individual random production history for one farmer that will be appropriately correlated with the corresponding historical county yield observations. Let $C$, the $K \times T$ correlated standard normal yield deviate matrix equal:

$$
C=A U,
$$

where $A$ is a $K \times K$ factored county-farm yield covariance matrix such that $A A^{\prime}=\Sigma, U$ is a $K \times T$ matrix of independent standard normal deviates, and $T$ is number of county yield observations. The total number of random variables is $K{ }^{9}$ Suppose $K-J$ of the random variables are already observed, we draw $J>\frac{K}{2}$ parametrically, where $C$ will be decomposed as follows:

$$
C=\left[\begin{array}{l}
C_{1} \\
C_{2}
\end{array}\right],
$$

where, $C_{1}$ is a $J \times T$ submatrix of values to be drawn parametrically (farm unit yield deviates), and $C_{2}$ is a $(K-J) \times T$ submatrix of predetermined values (county yield deviates). ${ }^{10}$ Analogically $U$ is decomposed as

$$
U=\left[\begin{array}{l}
U_{1} \\
U_{2}
\end{array}\right],
$$

where $U_{1}$ and $U_{2}$ are $J \times T$ and $(K-J) \times T$ standard normal draws, respectively. Note that, if a farmer has more than one tract of land, it will be captured in $C_{1}$ and $U_{1}$ by appropriate dimension, $J$. The factored covariance matrix, $A$, is upper triangular and has the following components.

$$
A=\left[\begin{array}{cc}
A_{11} & A_{12} \\
0 & A_{22}
\end{array}\right]
$$

\footnotetext{
${ }^{8}$ For brevity, here we only describe a general formula for base rate calculation and omit the equations that calculate total premium rates as the latter depends on policy type, unit structure, and other factors. The details are provided in the M-13 handbook.

${ }^{9}$ For simplicity, if a hypothetical farmer has only one tract of land and produces only corn (used for basic and optional unit analysis), length of $K$ is 2 ( 1 for hypothetical farm yields and 1 for county yields). If a farmer produces corn on two different tracts of land (used for enterprise unit analysis), then $K$ is 3 ( 2 for hypothetical farm yields and 1 for county yields).

${ }^{10}$ Length of $J$ depends on the number of variables that need to be drawn parametrically. Using examples from footnote 9 , length of $J$ will be 1 and 2, respectively.
} 
Simple matrix multiplication yields

$$
C_{1}=A_{11} U_{1}+A_{12} U_{2}
$$

and

$$
C_{2}=A_{22} U_{2},
$$

where $C_{1}$ contains farm-level correlated yield deviates and $C_{2}$ contains county-level correlated yield deviates. In this procedure, $A$ matrix is predetermined and the details are provided in Section 4.4. To combine all the information, the entire process is summarized.

Step 1, for a given SCCTP combination, we run a simple regression of a county yield on a time trend and obtain residuals:

$$
\widehat{y}_{c}=\beta_{0}+\beta_{1} \times \text { Trend }
$$

and

$$
\widehat{e}=y_{c}-\widehat{y}_{c},
$$

where $\hat{e}$ is employed as $C_{2}$ from above.

Step 2, we obtain $U_{2}$

$$
U_{2}=A_{22}^{-1} C_{2} \text {. }
$$

Step 3, we draw $U_{1}$ independent standard normal deviates.

Step 4 , we calculate an individual farm-level standard normal yield deviate, $C_{1}$.

$$
C_{1}=A_{11} U_{1}+A_{12} U_{2}
$$

Step 5, we use farm-level yield deviates to generate random farm-level yields, $\hat{y}_{f}$, that will be used for the insurance analysis

$$
\widehat{y}_{f}=\mu+C_{1},
$$

where $\mu$ is the mean of untruncated farm yields. Finally, we repeat Steps 3-5 $n$ times to obtain individual farm-level yields for $n$ farmers within a given county.

To generate the $A$ matrix and $\mu$ for a given SCCTP combination, we need to specify a countyindividual farm yield correlation, implied standard deviations of farm yields, and the mean of the untruncated yield distribution. Assuming a truncated (at zero) normal distribution, we know the distribution has mean

$$
m=\mu+\frac{\phi(\gamma)}{z}
$$

and a cumulative distribution function (CDF) defined as

$$
F(y)=\frac{\Phi\left(\frac{y-\mu}{\sigma}\right)-\Phi(\gamma)}{z}
$$

where $\mu$ and $\sigma$ are the mean and variance of the untruncated distribution, $\gamma=-\frac{\mu}{\sigma}$ and $z=1-\Phi(\gamma)$, where $\Phi$ is the standard normal CDF, with corresponding probability distribution function $\varphi$.

To obtain $m$, we use the reference yield for a given SCCTP obtained from RMA's ADM database. For $F(y)$, we first find the most popular insured coverage level for a given SCCTP, where the most popular coverage level is obtained through referring RMA's Summary of Business and selecting the level that had the highest acres insured. Next, we use this coverage level and apply premium-implied CDF methodology derived by Maisashvili et al. (2019) to find a corresponding CDF. In particular, Maisashvili et al. (2019) showed that premiums and other actuarial information for different coverage levels can be used to infer upper and lower bounds for a yield CDF at 
specific yield values. Thus, we have equations (23) and (24) with two unknowns: $\mu$ and $\sigma$. We use an unconstrained numerical optimization method to find joint solutions of both $\mu$ and $\sigma$. We use this method for every SCCTP combination.

To fully construct the factored covariance matrix, $A$, we need both county-farm and inter-farm correlation coefficients. Based on previous results in Gerlt, Thompson, and Miller (2014), these values were set as 0.25 and 0.75 , respectively. Thus,

$$
A=\sqrt{S R S^{\prime}}
$$

where $S$ is a diagonal standard deviation matrix of farm and county yields and $R$ is a farm-county yield correlation matrix. In order for the matrix to be Cholesky decomposable, the entire matrix must be positive definite. We found that this was not an issue for the analysis. For calculating the changes in producer premiums, total premiums, subsidies, and expected utility, the changes are calculated following the procedures discussed earlier.

\subsection{Policy scenarios}

The 2008 Farm bill provided an updated level of crop insurance subsidies across options on how to divide land into insurance units. The three types of insurance units are Basic Units (BU), Optional Units (OU), and Enterprise Units (EntU). Generally speaking, BU and OU are single owner, single crop units, where OU further sub-divide across production practices. EntU means that all acres of the same crop in the same county are combined. YP, RP, and RP-HPE policies are available for EntU. As mentioned, the EntU combines all acres of a single crop within a county in which the producer has a financial interest into a single unit, regardless of whether they are owned or rented, or how many landlords are involved. An EntU receives the same dollar subsidy as BU and OU, which results in a higher percent subsidy. The subsidy rates for EntU are sometimes as much as $20 \%$ higher than for the same coverage relative to BU and OU structures. According to RMA's Summary of Business, participation data from 2009-2018 reveal the EntU are far more popular for corn and soybean farmers than for other crops. Approximately 53\% of corn acres and 52\% of soybean acres are covered under the EntU option. As a comparison, only $33 \%$ of cotton, $29 \%$ of grain sorghum, and $27 \%$ of wheat acres are covered as EntU.

We analyze a baseline along with three subsidy scenarios. Under the base case, we calculate the set of choices and select the best combinations for each hypothetical farmer following the expected utility maximization methodology described earlier. In Scenario 1, we study the implications of subsidy changes at the higher coverage levels, assuming all applicable insurance policy options remain intact (i.e., YP, RP, RP-HPE). In particular, we calculate the new set of risk-return profiles for all possible combinations, where subsidy rates at coverage levels greater than $70 \%$ are set to $0 \%$, and the subsidy rates at lower coverage levels remain unchanged. Therefore, this scenario assumes that producers who decide to sign up for higher coverage levels pay the full price. For Scenario 2, we study the implications of removing the subsidies at all coverage levels, assuming current policy options remain unchanged. Finally, for Scenario 3, we study the implications of eliminating the RP policy option, leaving YP and RP-HPE as the only available options, and assume the current subsidy rates remain intact. The details of all subsidy scenarios are summarized in Table 1.

\subsection{Model validation}

Before analyzing the alternative policy scenarios, we run the baseline scenario, assuming current subsidy levels and available policy options. This is conducted for nonirrigated production practices for corn, soybeans, and winter wheat, and the results are compared to observed behavior from the 2018 Summary of Business data. For each SCCTP combination, we generated random yields for 20 representative hypothetical farmers, using the methodology discussed earlier. The Summary of Business data provided the number of insured acres per county for a given crop 
Table 1. Subsidy scenario description across coverage levels

\begin{tabular}{|c|c|c|c|c|c|c|c|c|}
\hline \multirow[b]{2}{*}{$\begin{array}{l}\text { Coverage } \\
\text { Level \% }\end{array}$} & \multicolumn{2}{|c|}{ Base } & \multicolumn{2}{|c|}{ Scenario 1} & \multicolumn{2}{|c|}{ Scenario 2} & \multicolumn{2}{|c|}{ Scenario 3} \\
\hline & $\begin{array}{c}\text { Basic Units } \\
\text { and Optional } \\
\text { Units } \\
\text { Subsidy (\%) }\end{array}$ & $\begin{array}{l}\text { Enterprise } \\
\text { Units } \\
\text { Subsidy } \\
(\%)\end{array}$ & $\begin{array}{l}\text { Basic } \\
\text { Units and } \\
\text { Optional } \\
\text { Units } \\
\text { Subsidy } \\
\text { (\%) }\end{array}$ & $\begin{array}{l}\text { Enterprise } \\
\text { Units } \\
\text { Subsidy } \\
(\%)\end{array}$ & $\begin{array}{l}\text { Basic } \\
\text { Units and } \\
\text { Optional } \\
\text { Units } \\
\text { Subsidy } \\
(\%)\end{array}$ & $\begin{array}{l}\text { Enterprise } \\
\text { Units } \\
\text { Subsidy } \\
(\%)\end{array}$ & $\begin{array}{l}\text { Basic } \\
\text { Units and } \\
\text { Optional } \\
\text { Units } \\
\text { Subsidy } \\
(\%)\end{array}$ & $\begin{array}{c}\text { Enterprise } \\
\text { Units } \\
\text { Subsidy } \\
(\%)\end{array}$ \\
\hline 50 & 67 & 80 & 67 & 80 & 0 & 0 & 67 & 80 \\
\hline 55 & 64 & 80 & 64 & 80 & 0 & 0 & 64 & 80 \\
\hline 60 & 64 & 80 & 64 & 80 & 0 & 0 & 64 & 80 \\
\hline 65 & 59 & 80 & 59 & 80 & 0 & 0 & 59 & 80 \\
\hline 70 & 59 & 80 & 59 & 80 & 0 & 0 & 59 & 80 \\
\hline 75 & 55 & 77 & 0 & 0 & 0 & 0 & 55 & 77 \\
\hline 80 & 48 & 68 & 0 & 0 & 0 & 0 & 48 & 68 \\
\hline 85 & 38 & 53 & 0 & 0 & 0 & 0 & 38 & 53 \\
\hline Available & YP, RP, & $\mathrm{YP}, \mathrm{RP}$, & $\mathrm{YP}, \mathrm{RP}$, & YP, RP, & YP, RP, & $\mathrm{YP}, \mathrm{RP}$ & YP & YP \\
\hline Policies & RP-HPE & RP-HPE & RP-HPE & RP-HPE & RP-HPE & RP-HPE & RP-HPE & RP-HPE \\
\hline
\end{tabular}

Note: $\mathrm{YP}=$ Yield Protection, RP $=$ Revenue Protection, and RP-HPE $=$ Revenue Protection with Harvest Price Exclusion.

by irrigation practice and unit structure for which the policy was issued. For policies that were sold under $\mathrm{BU}$ and $\mathrm{OU}$, we assumed that these farmers were not eligible for the EntU option. Considering that we do not have data of individual farmers and the Summary of Business data are aggregated, we would not know if signing up under BU or OU is a matter of eligibility or simply a choice. Therefore, we matched the unit structure choices exactly as they were listed in the Summary of Business data and run the analysis for available policies and coverage levels. For each SCCTP, we used the number of insured acres provided by the Summary of Business data and assigned them to these hypothetical farmers based on unit structure, to ensure that both actual and simulated insured acres were identical. ${ }^{11}$ In total, we analyzed 63 million acres of dryland corn, 60 million acres of dryland soybeans, and 12 million acres of dryland winter wheat.

Results from this validation exercise are summarized below. Figure 1 shows how the expected utility maximization model results compare to the actual choices made by farmers from the Summary of Business data for the 2018 insurance year for dryland corn, soybeans, and winter wheat. The left-hand side of each figure shows the dollar amount of liability per acre for each county. Our calculated liabilities per acre, with some minor exceptions, closely matched with the dollar liabilities retrieved from the Summary of Business data. In particular, the results from the baseline scenario indicated the average dollar per acre liability, across for all states and counties, is approximately $\$ 505$ for corn, $\$ 380$ for soybeans, and $\$ 150$ for winter wheat, compared to the Summary of Business results of $\$ 507, \$ 374$, and $\$ 147$, respectively.

The right-hand side of each figure represents insurance policy and coverage level choices, measured in acres. The replication results show that our model slightly over-selects YP and RP-HPE policies, where the actual results show that people predominantly select an RP policy. This result is not surprising considering that YP is significantly cheaper than RP. In the opposite case, where our model selected YP instead of RP, the difference between the simulated expected revenues of

\footnotetext{
${ }^{11}$ In other words, for a given SCCTP, we looked at the Summary of Business data and calculated the number of acres that were insured under $\mathrm{BU}, \mathrm{OU}$, and $\mathrm{EntU}$ and matched the unit structure choices correspondingly.
} 
(a)

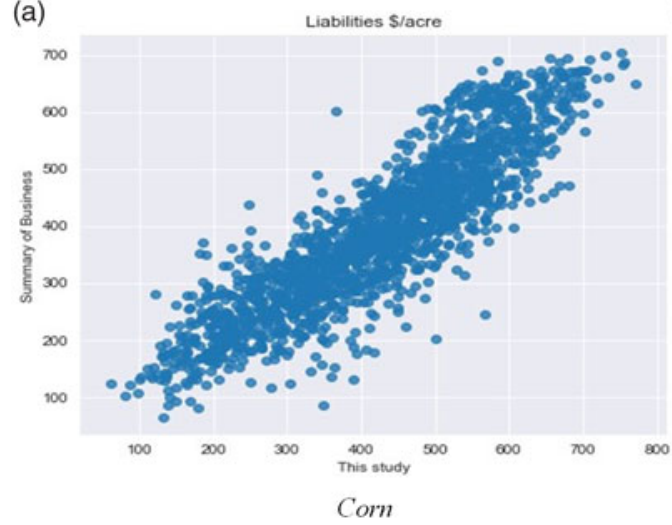

(c)
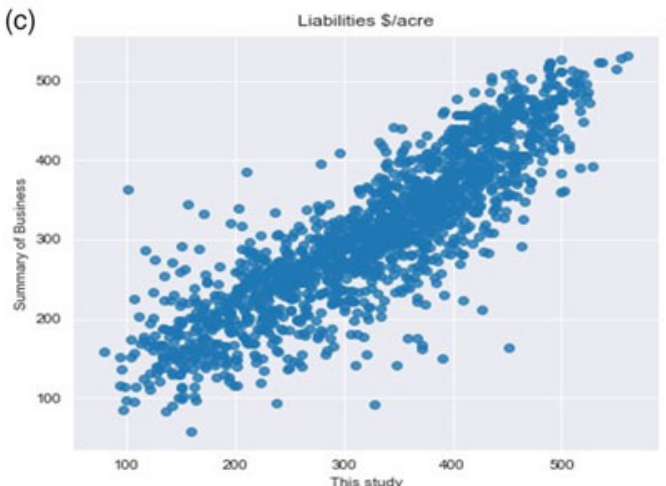

Soybeans

(e) Liabilities \$/acre

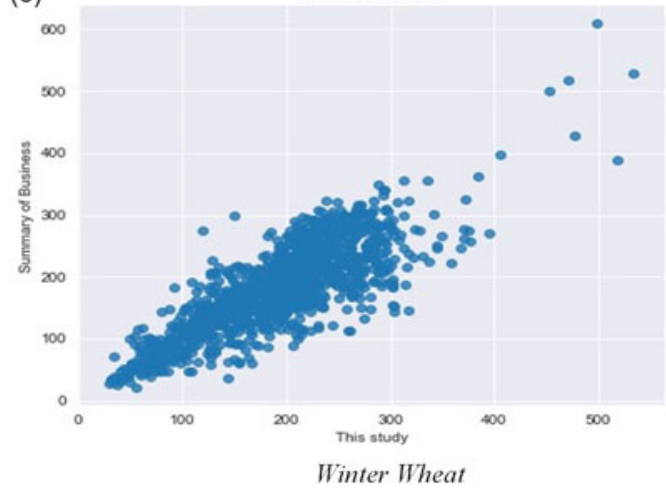

(b)

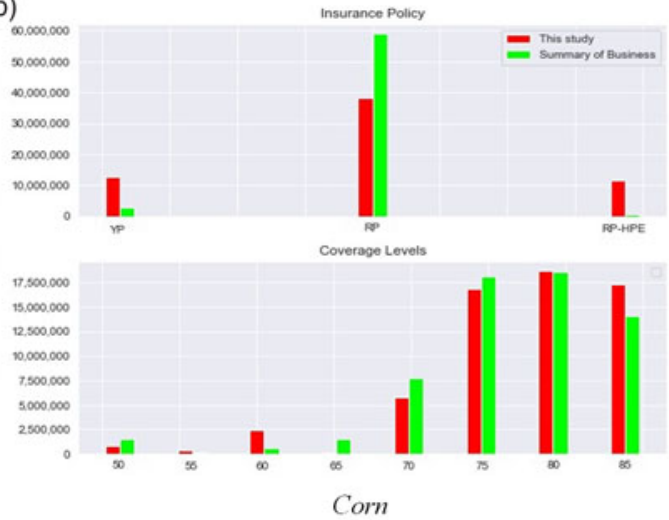

(d)

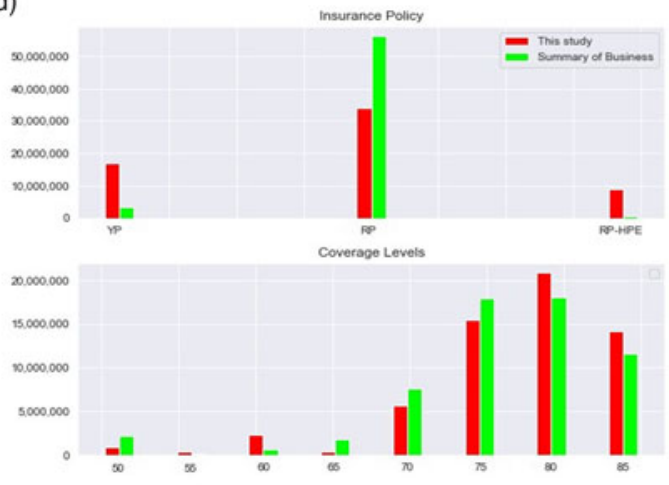

Soybeans

(f)

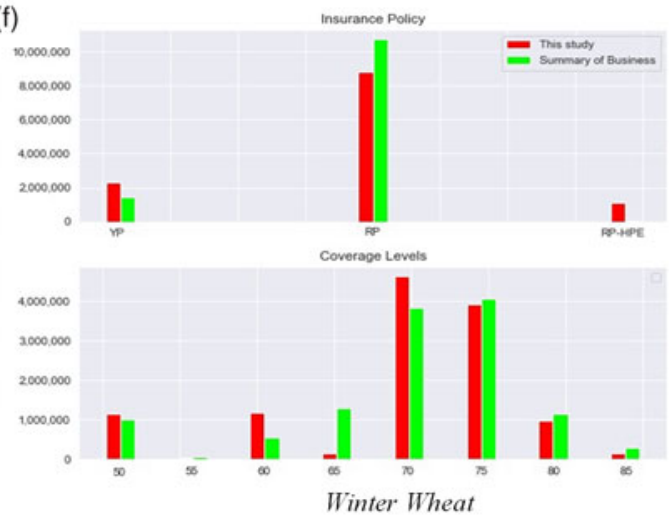

Figure 1. Corn, soybean, and wheat results, this study vs. Summary of Business. Note: YP = Yield Protection, RP $=$ Revenue Protection, and RP-HPE $=$ Revenue Protection with Harvest Price Exclusion.

$\mathrm{RP}$ and YP was not big enough to outweigh the difference in premium costs between the two policies. The difference was most notably observed for corn and soybeans, where model results indicated that RP polices were found to be optimal for just under 40 million acres, where the actual insured acres are just over 50 million acres. For winter wheat, we see model results closer to the Summary of Business data. Our model chose an RP policy for about 9 million acres, where the actual acres were just over 10 million. It is worth noting that in the counties where our model selected YP instead of RP, the PVEUs of YP and RP were very similar. 
When comparing coverage level choices, the differences between our study and the data were minimal. The most popular coverage levels for corn and soybeans were 75,80 , and $85 \%$, respectively, and for winter wheat 70,75 , and $80 \%$, respectively. In the case of corn and soybeans, our analysis slightly over-selected $80 \%$ and $85 \%$ coverage levels and negligibly under-selected the $75 \%$ coverage level. In the case of dryland winter wheat, our results slightly over-selected $70 \%$ coverage levels and trivially under-sampled the $80 \%$ and $85 \%$ coverages. The results of our analysis showed that the combined insured acres under the three most selected coverage levels for corn, soybeans, and winter wheat were 52.7, 50.3, and 9.5 million acres, respectively, when compared to the actual Summary of Business results of 51.4, 47.4, and 9.2 million acres, respectively.

Considering that our analysis is based solely on expected utility maximization, the framework does ignore several observable factors likely important to insurance decision making, such as budget constraints, institutional restrictions (e.g., lender requirements), and information limitations. Therefore, our baseline scenario results were not expected to perfectly replicate the choices observed in the Summary of Business data. However, overall we believe the model adequately represents producer insurance choices, and is appropriate for evaluating alternative policy scenarios.

\section{Results}

As an illustration before comparing the current policy to alternative policy scenarios, we present the values of the baseline scenario. The combined 134 million acres of nonirrigated corn, soybeans, and winter wheat have been analyzed. As described above, for each SCCTP combination, we randomly generated 20 individual farm-level yield histories for representative farmers from county yield data using the correlation induction methodology discussed in part IV. Then, for each of 20 representative farmers for given SCCTP combination, we selected the insurance combination that maximized PVEU using equation (4). The baseline results showed that for nonirrigated corn the sum of total premiums, producer premiums and subsidies were $\$ 2.7$ billion, $\$ 1.2$ billion and $\$ 1.5$ billion, respectively. For nonirrigated soybeans the sum of total premiums, producer premiums and subsidies accounted $\$ 1.7$ billion, $\$ 0.7$ billion and $\$ 1.0$ billion, respectively. With regards to nonirrigated winter wheat, the aggregate collected total premiums, producer premiums and subsidy payments accounted $\$ 278$ million, $\$ 88$ million and $\$ 190$ million, respectively. Then, for each SCCTP combination and for each of 20 representative farmers the policy combination that produced the highest PVEU, the ENR values were calculated using equation (1). The baseline results showed that the aggregate ENR values for nonirrigated corn, soybeans and winter wheat were $\$ 43$ billion, $\$ 31$ billion and $\$ 2.7$ billion, respectively.

The aforementioned methodology was used to study the implications of 3 different subsidy scenarios as presented in Table 1. The nature of changes in producer choices for corn, soybeans and winter wheat for coverage levels and insurance policies are depicted using Sankey diagrams in Figures 2 through 4 . All three crops were combined into a single Sankey diagram for each subsidy scenario as the changes observed across crops were similar. Panel (a) in each figure represents the change in coverage level, while panel (b) depicts the change in insurance policy type, each represented in total insured acres and using a different color. The left-hand side of each Sankey diagram represents the current selections across coverage levels and policies, with each color distinctly representing a specific choice. The right side indicates the predicted selection for an alternative policy scenario, where the new selection is represented by the vertical colored line bordering the right side, corresponding with the colors from the original baseline selections. The curved lines connecting the left and right sides of the Sankey diagram represent changes in optimal choices between the baseline and subsidy scenarios, for both coverage level in (a), and policy choice in (b). Both sides of each graph show the flow of number insured acres from baseline to alternative scenarios, represented in terms of coverage levels and insurance policies (left and right, 
(a)

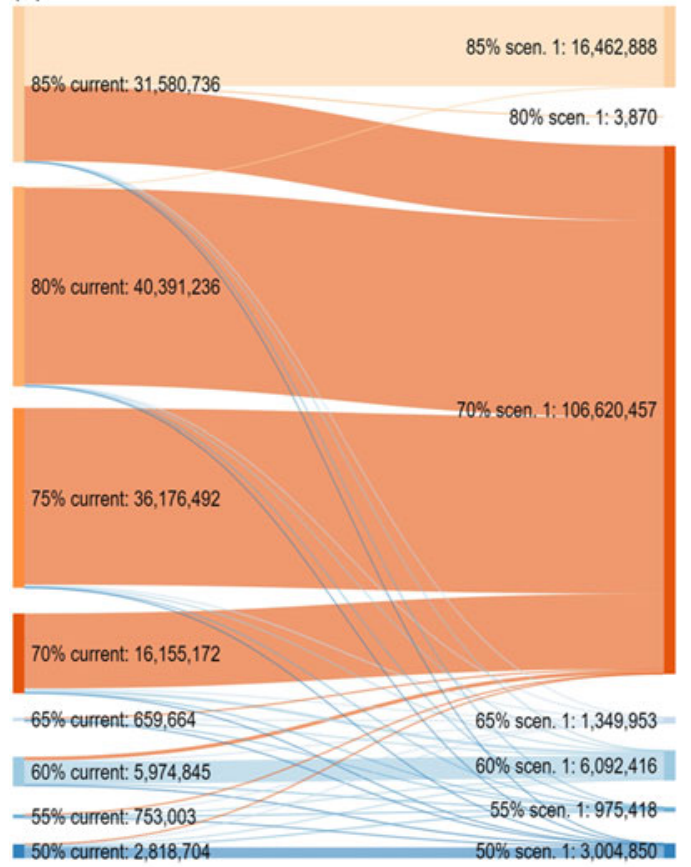

(b)

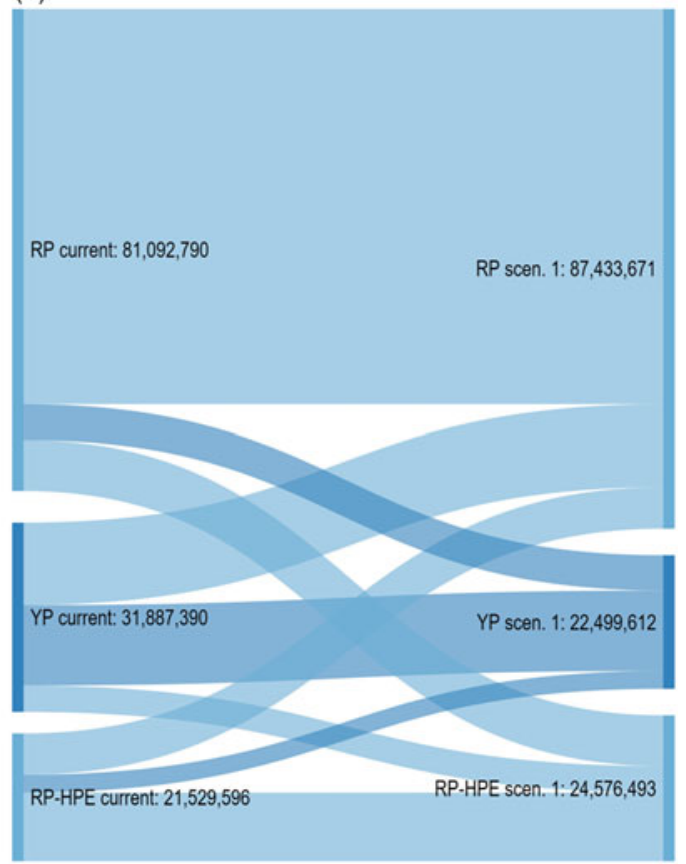

Figure 2. Predicted changes in coverage levels and insurance policies among nonirrigated corn, soybean, and winter wheat acres due to Scenario 1.

Note: $\mathrm{YP}=$ Yield Protection, RP $=$ Revenue Protection, and RP-HPE $=$ Revenue Protection with Harvest Price Exclusion.

respectively). The changes in collected total premiums, producer premiums, government subsidies, and ENRs for each crop due to alternative policy implications are summarized in Table $2 .{ }^{12}$

\subsection{Results of Scenario 1}

The implications of removing subsidies at $75 \%$ coverage levels and above are presented through a Sankey diagram in Figure 2. As expected, significant acres from high coverage levels move to the 70\% level, where they are eligible for subsidies. Around 106 million acres are projected to be insured at the $70 \%$ coverage level in this scenario, which is about $80 \%$ of total insured acres analyzed. The aggregate insured acres at 75, 80, and 85\% coverage levels, respectively, decrease from 108 million to just under 17 million. No major changes are observed at coverage levels below $70 \%$ level, except for the $65 \%$ level, where the insured acres double from 0.65 million to 1.3 million. Relatively minor changes are noticed in terms of insurance policy choice. About 6 million acres more are projected to be insured under RP, an increase from 81 to 87 million when compared to the current policy. Approximately 9 million fewer acres are insured at YP, a decrease from 31.8 to 22.5 million. Minor changes are observed for RP-HPE policy, where insured acres increase from 21.5 to 24.5 million.

Changes in total premiums collected, producer premiums, subsidies, and ENRs are calculated using the 2018 data and presented in Table 2. As a result of removing premium subsidies at and above $75 \%$ coverage levels, we project a decrease in total premiums collected, approximately by $\$ 980$ million, for all three crops combined. This results in a decrease of collected producer premiums by $\$ 415$ million and reduction of subsidies paid by $\$ 565$ million. Implications of changes

\footnotetext{
${ }^{12}$ The model was also run for the year 2017, and the results are presented in Table A9 in the Appendix. Although there are some minor quantitative differences, the 2017 results are qualitatively identical to those for 2018 .
} 
Table 2. Predicted changes in total premiums, producer premiums, subsidies, and expected net returns due to three policy implications when compared to the base

\begin{tabular}{|c|c|c|c|c|}
\hline $\begin{array}{l}\text { Relative Risk } \\
\text { Aversion }=2.5\end{array}$ & $\begin{array}{l}\text { Change in } 2018 \text { Total } \\
\text { Premiums Collected } \\
\text { (Million \$) }\end{array}$ & $\begin{array}{l}\text { Change in } 2018 \text { Producer } \\
\text { Premiums Collected } \\
\text { (Million \$) }\end{array}$ & $\begin{array}{l}\text { Change in } 2018 \\
\text { Subsidies Paid } \\
\text { (Million \$) }\end{array}$ & $\begin{array}{c}\text { Change in } 2018 \\
\text { Expected Net Returns } \\
\text { (Million \$) }\end{array}$ \\
\hline & \multicolumn{4}{|c|}{ Scenario 1} \\
\hline Corn & -533.3 & -210.9 & -322.4 & -839.0 \\
\hline Soybeans & -419.8 & -191.4 & -228.4 & -618.2 \\
\hline Winter wheat & -27.5 & -12.5 & -15.0 & -26.5 \\
\hline \multirow[t]{2}{*}{ Total } & -980.6 & -414.8 & -565.8 & -1483.6 \\
\hline & \multicolumn{4}{|c|}{ Scenario 2} \\
\hline Corn & -867.7 & 474.5 & -1342.3 & -1687.9 \\
\hline Soybeans & -622.2 & 345.6 & -967.8 & -1173.0 \\
\hline Winter wheat & -128.2 & 61.1 & -189.3 & -216.4 \\
\hline \multirow[t]{2}{*}{ Total } & -1618.1 & 881.2 & -2499.4 & -3077.4 \\
\hline & \multicolumn{4}{|c|}{ Scenario 3} \\
\hline Corn & -290.8 & -68.3 & -222.5 & -253.7 \\
\hline Soybeans & -159.9 & -29.5 & -130.4 & -111.8 \\
\hline Winter wheat & -25.7 & -6.4 & -19.3 & -18.9 \\
\hline Total & -476.5 & -104.3 & -372.1 & -384.4 \\
\hline
\end{tabular}

Changes in subsidies and changes in the producer premiums may not sum to changes in total premiums due to rounding.

in ENRs are more pronounced. The aggregate loss in ENR, due to subsidy removals at high coverage levels, is projected to be $\$ 1.4$ billion. The magnitude of decrease in ENR to producers is substantially higher than the savings from reduced subsidy payments. Intuition might suggest that change in producer ENRs should not be much larger than changes in subsidy payments. Farmers always have an option to stay with the current choice, in which case change in ENR will be exactly equal to change in subsidy payments. However, as it turns out, the ability of producers to change their choices results in this not being the case. As an example, consider a typical nonirrigated corn producer in Allamakee county, Iowa. For simplicity, suppose the producer is risk neutral with approved yield of $175 \mathrm{bu}$./acre and that the projected price is $\$ 3.95 / \mathrm{bu}$. Under the baseline scenario, among all available choices, $85 \%$ YP coverage yields the maximum ENR. For this combination, the total premium per acre is $\$ 21.30$, the producer premium is $\$ 13.20$, the subsidy payment is $\$ 8.10$, and the simulated ENR is $\$ 703.00$ /acre. Under Scenario 1, when the subsidies are removed at $75 \%$ and above, the producer could keep this $85 \%$ coverage and would enjoy an ENR of $\$ 694.90$ ( $\$ 703.00$ minus the subsidy of $\$ 8.10$, which has been eliminated). However, under Scenario 1, the producer actually prefers $70 \%$ coverage, as it yields a slightly higher ENR of $\$ 695.00$. The total premium, producer premium, and subsidy under $70 \%$ coverage are $\$ 9.08$, $\$ 3.73$, and $\$ 5.35$, respectively. Given that the producer now chooses the $70 \%$ coverage, relative to the base scenario the subsidy has declined by $\$ 2.75$ (having gone from $\$ 8.10$ to $\$ 5.35$ ), even though the ENR has declined by $\$ 8.00$ (having gone from $\$ 703.00$ to $\$ 695.00$ ).

\subsection{Results of Scenario 2}

The results of Scenario 2 are presented in Figure 3. This scenario assumes that all premium subsidies disappear, and the producer is responsible for paying the full insurance price while retaining 
(a)

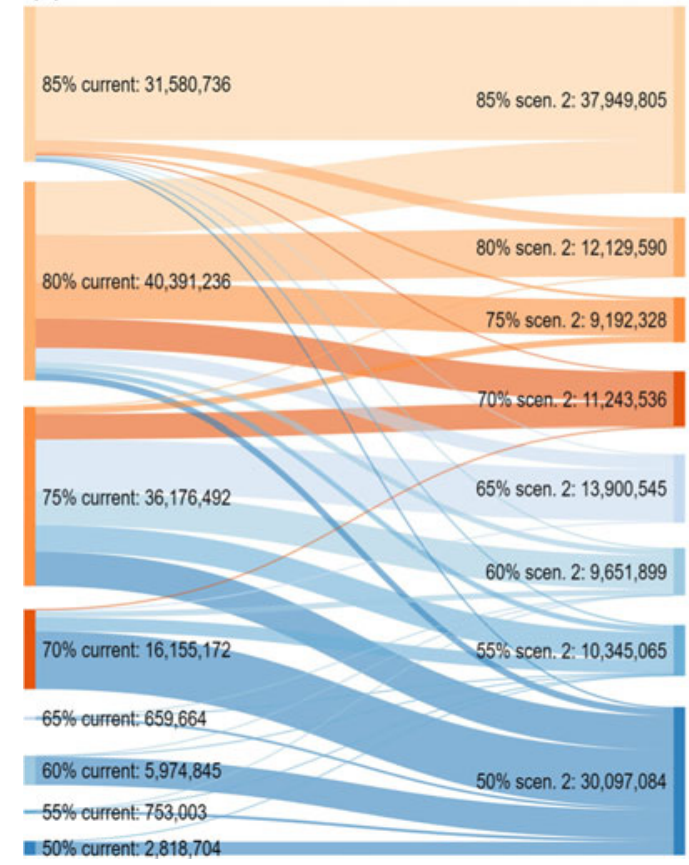

(b)

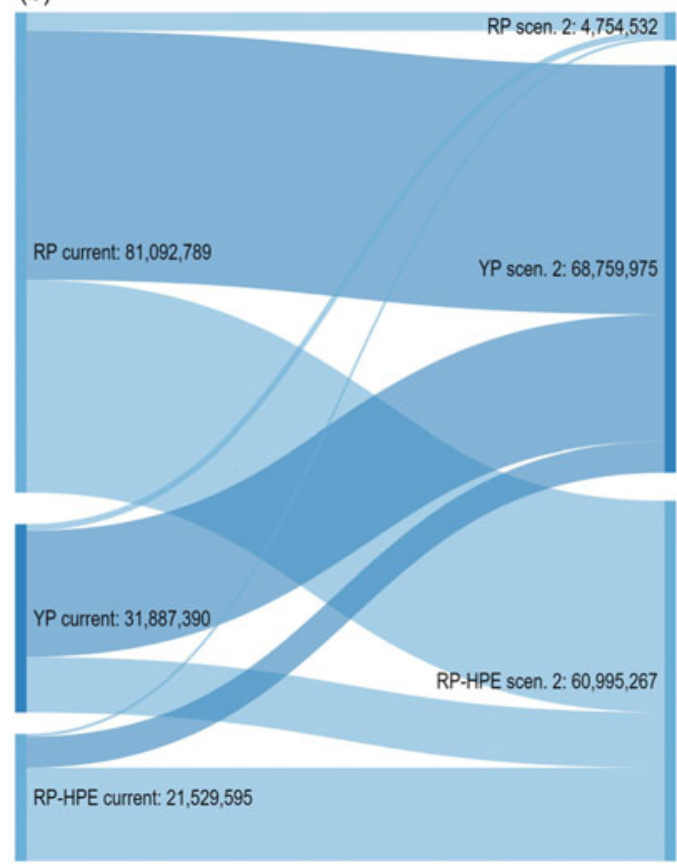

Figure 3. Predicted changes in coverage levels and insurance policies among nonirrigated corn, soybean, and winter wheat acres due to Scenario 2.

Note: $\mathrm{YP}=$ Yield Protection, $\mathrm{RP}=$ Revenue Protection, and RP-HPE $=$ Revenue Protection with Harvest Price Exclusion.

all current policy options. As expected, this scenario has the most noticeable fiscal impacts. The most notable changes for coverage levels are observed at $75 \%$ and $80 \%$ coverage levels. Most of the acres covered at the $75 \%$ level move to the lower coverage levels, a decrease from 36.1 million acres to 9.1 million, where the majority of acres covered at $80 \%$ level move towards the $85 \%$ level. The number of acres insured under $80 \%$ level is projected to decrease from 40.4 million to 12 million, a substantial change. Although there is a noticeable increase from the $80 \%$ level to $85 \%$ level, the majority of these movements are accompanied by switching from RP to YP insurance policies.

In terms of insurance policy implications, the RP is projected to be the least attractive option considering it is the most expensive policy to purchase without subsidies. The number of acres insured under RP policy is projected to decrease from 81 million to just under 5 million, approximately a $94 \%$ decrease. Most of the acres move towards YP, where the number of acres insured at YP is projected to increase from 31.8 million to 68.7 million, a $116 \%$ increase.

Table 2 shows the fiscal consequences of the removal of subsidy rates at all coverage levels. The total collected premiums are projected to decrease by $\$ 1.6$ billion. The collected producer premiums, costing the same as the total premiums for this scenario, are projected to increase by $\$ 881$ million. Consequently, subsidy payments are projected to decrease by $\$ 2.5$ billion. The removal of subsidy rates at all coverage levels has consequences on ENR totals, where total change in ENR is projected to decrease by $\$ 3$ billion. This is about twice as high than the aggregate change found in Scenario 1. The removal of all subsidy rates is projected to reduce producers' ENR terms more than the potential value of government subsidy savings. The aggregate changes in ENR are slightly higher than the projected changes in subsidy payments. However, this result is sensitive to risk attitude assumptions. The result holds for only moderately risk averse and very risk averse individuals. The consequences are different for individuals who are either nearly risk neutral or hardly risk averse (see Appendix, Table A1). In particular, decreasing risk aversion 
(a)

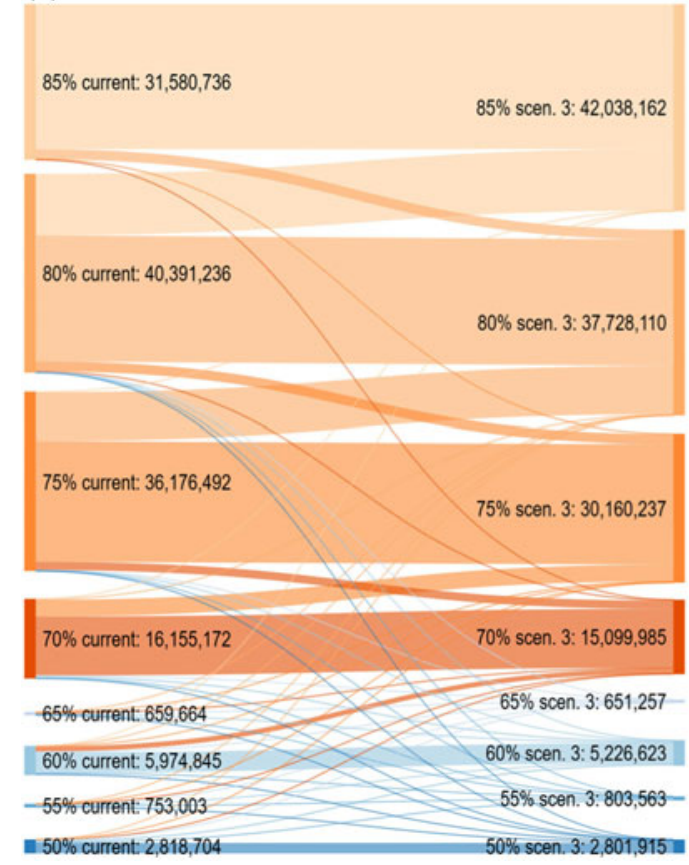

(b)

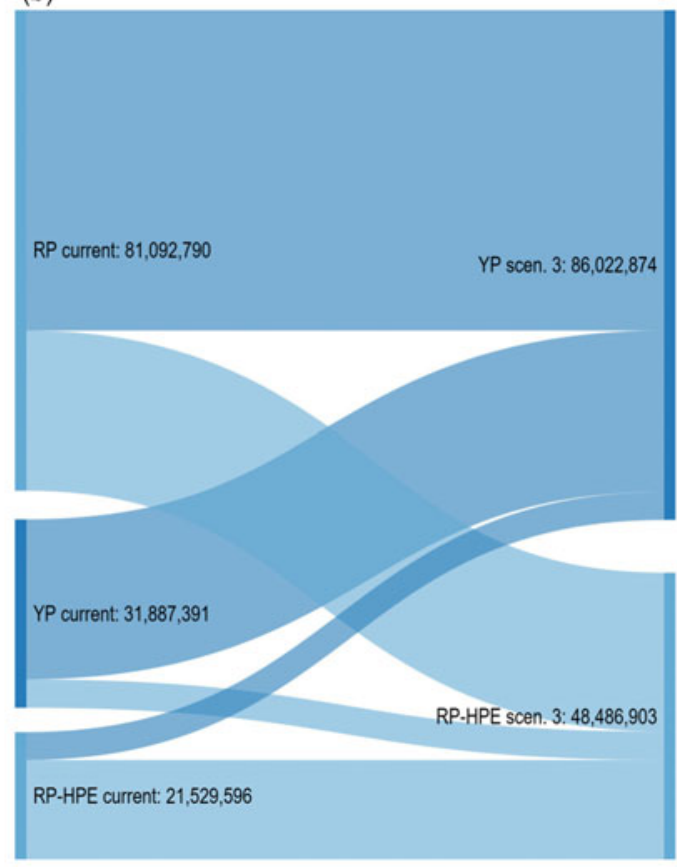

Figure 4. Predicted changes in coverage levels and insurance policies among nonirrigated corn, soybean, and winter wheat acres due to Scenario 3.

Note: YP $=$ Yield Protection, RP $=$ Revenue Protection, and RP-HPE $=$ Revenue Protection with Harvest Price Exclusion.

reduced the gap between subsidy payment value and ENR change. The aggregate changes in ENR are less than aggregate changes in subsidy payments for individuals with minimal aversion to risk.

\subsection{Results of Scenario 3}

The results of Scenario 3 are depicted in Figure 4. Scenario 3 assumes the current subsidy rates remain intact, but the plain RP becomes unavailable, leaving YP and RP-HPE as the only viable policy options. The most noticeable change for coverage levels is observed at the $85 \%$ level, with an increase from 31.6 million to 42 million acres. Most of these acres move from the $80 \%$ level in the baseline, a switch from $80 \%$ coverage with RP to $85 \%$ coverage with a YP policy. The change at the $80 \%$ coverage level, by itself, is not substantial, a decrease from 40.4 million to 37.7 million. Although a large portion of $80 \%$ coverage level acres is moving to the $85 \%$ level, a large portion of acres is moving from RP-75\% coverage to the YP-80\% level, which explains the small aggregate change at the $80 \%$ level itself. Most of the acres initially in RP in the baseline move into YP, showing an increase from 31.8 million to 86 million acres. The remaining portion of acres is diverted towards RP-HPE, increasing from 21.5 million to 48.5 million acres.

From Table 2, removal of the RP creates a projected decrease in total premiums collected of approximately $\$ 476$ million. The collected producer premiums decrease by only $\$ 104$ million, whereas subsidy payments are projected to decrease by around $\$ 372$ million. The loss of ENR due to RP removal, assuming individuals are moderately risk averse individuals, is approximately $\$ 384$ million, almost identical to the projected change in subsidy payments.

What is more, changes in ENR for soybeans and winter wheat are less than changes in subsidy payments. This implies that the cost of subsidizing a RP policy compared to a YP policy is about 
the same as the extra benefit received from signing up for RP. In a sensitivity experiment, we find this result also holds when both RP and RP-HPE policies are made unavailable. ${ }^{13}$

\section{Implications}

We constructed an agent-based expected utility crop insurance choice model to assess the impact of changing national crop insurance program parameters on representative farmers. Several scenarios were analyzed across subsidy and policy options and were found to have significantly different farmer behavioral responses and economic implications. When premium subsidies were eliminated at $75 \%$ coverage levels and above, or disappeared altogether, while retaining all insurance policy options, aggregate savings received in subsidy payments are projected to be lower than the aggregate loss in farmer expected net revenue estimates. For moderately risk averse individuals, in a case where subsidies disappear at all coverage levels, government subsidy payment savings are projected to be $\$ 2.5$ billion, on average, while ENR loss is estimated at $\$ 3$ billion. This relationship changes across risk preference assumptions. For minimally risk averse individuals, the ENR loss is estimated to be lower than the savings in subsidy payments. In the scenario where RP was removed as an insurance policy option, subsidy payment savings exceeded the loss in producer ENR for soybean and winter wheat producers, which was consistent across risk preference assumptions. For corn producers, loss in ENR was just slightly higher than savings in subsidy payments. On aggregate, savings from subsidy payments were estimated at $\$ 372$ million, and the ENR loss to producers was about $\$ 384$ million, on average. These results reveal that changes in producer welfare may be larger than intuition suggests based on the subsidy savings generated, due to changes in producer choices that would be triggered. Given this, policy makers should consider the effects of possible policy changes using a framework that reflects the fine-grained details of the change, the effects of the change across the full spectrum of choices open to producers, and the likely changes in producer choices.

Limitations of this study include the unavailability of farm-level cost data and initial budget constraints when characterizing producer behavior. Future research may incorporate per unit of output cost estimates; however, incorporating the heterogeneity across producers would pose additional challenges. Additionally, this model assumes crop yield variability is stationary, however, if this framework were to be applied in a dynamic context, this assumption may not be appropriate (McCarl, Villavicencio, and $\mathrm{Wu}, 2008$ ). More recent analyses have stressed the importance of adaptation and regional variation, signaling a need for future agent-based production models at a much more disaggregated scale to represent the United States (Kukal and Irmak, 2018).

With crop insurance complexity in the United States increasing significantly over time, improving our understanding of the impacts and interactions across policy types and subsidy levels is essential for policy makers to promote efficient crop insurance options for producers. This research presents only a small subset of viable policy options; however, future analyses can implement this framework to assess any number of policy alternatives, across subsidy levels, coverage levels, policy types, and crop eligibility. Additionally, this framework can be programmed to explore interactions across various policy combinations. An economic analysis across policy alternatives and incorporating farmer behavior is an important aspect when considering policy changes to such a critical component of our food supply and the national budget.

\footnotetext{
${ }^{13}$ In addition to global analysis, we decomposed the results into several regions to study the regional impacts of the policy changes for moderately risk averse individuals. The regional division is outlined in Table A3, provided in the Appendix. The analysis was decomposed into five regions: Corn Belt and Central Plains, Lake States, Northern Plains, Southeast, and Southern Plains, and all other regions. The results are provided in Tables A4-A8 in the Appendix. Although there are numerical differences across the regions, the implications are more or less similar when compared to the global results. The magnitude of the changes in total premiums, producer premiums, subsidy payments, and ENR are different considering the production differences. The largest change is observed, as expected, in Corn Belt and Central Plains regions, followed by Northern Plains, Southeast and Southern Plains, Lake States, and all other regions. The results are presented in the Appendix.
} 


\section{References}

Anderson, J.R., and J.B. Hardaker. "Risk Aversion in Economic Decision Making: Pragmatic Guides for Consistent Choice by Natural Resource Managers." Risk and Uncertainty in Environmental Economics. J. Wesseler, H.-P. Weikard, and R.D. Weaver, eds. Cheltenham, UK: Edward Elgar Publishing Ltd, 2003, pp. 172-88.

Anderson, J.R., and J.L. Dillon. Risk Analysis in Dryland Farming Systems. Rome, Italy: Food and Agriculture Organization, Tech. Rep. Farming Systems Management Series No. 2, 1992.

Babcock, B.A., and C.E. Hart. "Influence of the Premium Subsidy on Farmers' Crop Insurance Coverage Decisions." Center for Agricultural and Rural Development (CARD) Working Papers No. 05-WP 393, Ames, IA: CARD, 2005.

Bekkerman, A., E.J. Belasco, and V.H. Smith. Where the Money Goes. Washington, DC: American Enterprise Institute, Tech. Rep., 2018.

Coble, K.H., T.O. Knight, R.D. Pope, and J.W. Williams. "Modeling Farm-Level Crop Insurance Demand with Panel Data." American Journal of Agricultural Economics 78,2(1996):439-47.

Congressional Budget Office (CBO). Options for Reducing the Deficit: 2019 to 2028. Washington, DC: Congress of the United States, 2018.

Du, X., H. Feng, and D.A. Hennessy. "Rationality of Choices in Subsidized Crop Insurance Markets." American Journal of Agricultural Economics 99,3(2016):732-56.

Du, X., D.A. Hennessy, and H. Feng. “A Natural Resource Theory of US Crop Insurance Contract Choice.” American Journal of Agricultural Economics 96,1(2013):232-52.

Gardner, B.L., and R.A. Kramer. Experience with Crop Insurance Programs in the United States. Baltimore, MD: Johns Hopkins Univ. Press, Pub. for Internatl. Food Policy Research Inst., 1986.

Gerlt, S., W. Thompson, and D.J. Miller. "Exploiting the Relationship between Farm-Level Yields and County-Level Yields for Applied Analysis." Journal of Agricultural and Resource Economics 39,2(2014):253-270.

Glauber, J.W. “Crop Insurance Reconsidered." American Journal of Agricultural Economics 86,5(2004):1179-95.

Goodwin, B.K. "An Empirical Analysis of the Demand for Multiple Peril Crop Insurance." American Journal of Agricultural Economics 75,2(1993):425-34.

Goodwin, B.K., and V.H. Smith. "What Harm Is Done by Subsidizing Crop Insurance?" American Journal of Agricultural Economics 95,2(2013):489-97.

Goodwin, B.K., M.L. Vandeveer, and J.L. Deal. "An Empirical Analysis of Acreage Effects of Participation in the Federal Crop Insurance Program.” American Journal of Agricultural Economics 86,4(2004):1058-77.

Hardaker, J.B. Coping with Risk in Agriculture. Cambridge, MA: Cabi Publishing, 2004.

Harwood, J.L., R.G. Heifner, K.H. Coble, J.E. Perry, and A. Somwaru. Managing Risk in Farming: Concepts, Research, and Analysis. Washington, DC: U.S. Department of Agriculture, Economic Research Service, Agricultural Economic Report No. 34081, 1999.

Ifft, J., T. Kuethe, and M. Morehart. "Farm Debt Use by Farms with Crop Insurance." Choices 28,3(2013):1-5.

Just, R.E., and Q. Weninger. "Are Crop Yields Normally Distributed?" American Journal of Agricultural Economics 81,2(1999):287-304.

Kukal, M.S., and S. Irmak. "Climate-Driven Crop Yield and Yield Variability and Climate Change Impacts on the US Great Plains Agricultural Production.” Scientific Reports 8,1(2018):3450.

Letter to Congress. Joint Letter Opposing Amendments to Harm Crop Insurance. 2018. Internet site: https:// insurancenewsnet.com/oarticle/joint-letter-opposing-amendments-to-harm-crop-insurance

Maisashvili, A., H.L. Bryant, and J.W. Richardson. "Economic Feasibility of Tobacco Leaves for Biofuel Production and High Value Squalene." International Food and Agribusiness Management Review 19,4(2016):145-62.

Maisashvili, A., H.L. Bryant, G. Knapek, and J.M. Raulston. "Are Crop Insurance Premium-Implied Yield Distributions Valid?” Agricultural Finance Review 79,3(2019):467-90.

McCarl, B.A., X. Villavicencio, and X. Wu. "Climate Change and Future Analysis: Is Stationarity Dying?" American Journal of Agricultural Economics 90,5(2008):1241-47.

Monge, J.J., L.A. Ribera, J.A. da Silva, and J.W. Richardson. "Economics and Uncertainty of Lignocellulosic Biofuel Production from Energy Cane and Sweet Sorghum in South Texas." Journal of Agricultural and Applied Economics 46,4 (2014):457-85.

O'Donoghue, E. The Effects of Premium Subsidies on Demand for Crop Insurance. Washington, DC: U.S. Department of Agriculture, Economic Research Service, ERR No. 169, 2014.

Ramirez, O.A., S.K. Misra, and J.E. Field. Are Crop Yields Normally Distributed? Paper presented at the Annual Meeting of the American Agricultural Economics Association, Chicago, Illinois, August 5-8, 2001.

Richardson, J.W., B.K. Herbst, J.L. Outlaw, and R.C. Gill. "Including Risk in Economic Feasibility Analyses: The Case of Ethanol Production in Texas." Journal of Agribusiness 25,2(2007):115-32.

Serra, T., B.K. Goodwin, and A.M. Featherstone. "Modeling Changes in the US Demand for Crop Insurance during the 1990s." Agricultural Finance Review 63,2(2003):109-25.

Shaik, S., K.H. Coble, T.O. Knight, A.E. Baquet, and G.F. Patrick. "Crop Revenue and Yield Insurance Demand: A Subjective Probability Approach.” Journal of Agricultural and Applied Economics 40,3(2008):757-66. 
U.S. Department of Agriculture, Agricultural Resource Management Survey (USDA-ARMS). “ARMS Farm Financial and Crop Production Practices/Tailored Reports: Farm Structure and Finance.” 2018. Internet site: https://www.ers.usda.gov/ data-products/arms-farm-financial-and-crop-productionpractices/? modal=17882

U.S. Department of Agriculture, Farm Service Agency (USDA-FSA). “Farm Operating Loans.” 2019. Internet site: https:// www.fsa.usda.gov/programs-and-services/farm-loan-programs/farm-operating-loans/index

U.S. Department of Agriculture, Risk Management Agency (USDA-RMA). “Summary of Business.” 2018. Internet site: https://www.rma.usda.gov/SummaryOfBusiness

U.S. Department of Agriculture, Risk Management Agency (USDA-RMA). "RMA III/M-13 Handbook.” 2019a. Internet site: https://www.rma.usda.gov/Policy-and-Procedure/Appendix-III-M13-Handbook-Index/2019-Approved

U.S. Department of Agriculture, Risk Management Agency (USDA-RMA). "RMA P21 Handbook for RP and RP-HPE Indemnity Calculation.” 2019b. Internet site: https://legacy.rma.usda.gov/ftp/Publications/M13_Handbook/2019/ approved/P21_1_PLAN_01_INDEMNITY_CALCULATION.PDF

U.S. Department of Agriculture, Risk Management Agency (USDA-RMA). "RMA P21 Handbook for RP and RP-HPE Indemnity Calculation.” 2019c. Internet site: https://legacy.rma.usda.gov/ftp/Publications/M13_Handbook/2019/ approved/P21_2_PLAN_02_03_INDEMNITY_CALCULATION.PDF

White House. "Major Savings and Reforms in the President's 2020 Budget.” 2019. Internet site: https://www.whitehouse.gov/ wp-content/uploads/2019/03/msar-fy2020.pdf

Wright, B.D. "Multiple Peril Crop Insurance." Choices 29,3(2014):1-5.

Yi, J., H. Bryant, and J.W. Richardson. "How Do Premium Subsidies Affect Crop Insurance Demand at Different Coverage Levels: The Case of Corn." Geneva Papers on Risk and Insurance Practice. (2019):https://doi.org/10.1057/s41288019-00144-8

\section{Appendix}

Table A1. Predicted changes in total premiums, producer premiums, subsidies, and expected net returns due to three policy implications

\begin{tabular}{|c|c|c|c|c|}
\hline $\begin{array}{l}\text { Relative Risk } \\
\text { Aversion }=0.01\end{array}$ & $\begin{array}{l}\text { Change in } 2018 \text { Total } \\
\text { Premiums Collected } \\
\text { (Million \$) }\end{array}$ & $\begin{array}{c}\text { Change in } 2018 \text { Producer } \\
\text { Premiums Collected } \\
\text { (Million \$) }\end{array}$ & $\begin{array}{l}\text { Change in } 2018 \\
\text { Subsidies Paid } \\
\text { (Million \$) }\end{array}$ & $\begin{array}{c}\text { Change in } 2018 \\
\text { Expected Net Returns } \\
\text { (Million \$) }\end{array}$ \\
\hline & \multicolumn{4}{|c|}{ Scenario 1} \\
\hline Corn & -736.9 & -104.2 & -632.6 & -894.7 \\
\hline Soybeans & -646.9 & -139.5 & -507.5 & -682.3 \\
\hline Winter wheat & -91.3 & -54.8 & -36.4 & -45.7 \\
\hline \multirow[t]{2}{*}{ Total } & -1475.1 & -298.5 & -1176.5 & -1622.7 \\
\hline & \multicolumn{4}{|c|}{ Scenario 2} \\
\hline Corn & -383.7 & 1095.4 & -1479.0 & -1413.7 \\
\hline Soybeans & -390.3 & 699.8 & -1090.2 & -1026.8 \\
\hline Winter wheat & -109.9 & 112.7 & -222.7 & -202.9 \\
\hline \multirow[t]{2}{*}{ Total } & -884.0 & 1907.9 & -2791.8 & -2237.6 \\
\hline & \multicolumn{4}{|c|}{ Scenario 3} \\
\hline Corn & -529.3 & -234.5 & -294.8 & -357.3 \\
\hline Soybeans & -361.8 & -160.9 & -200.9 & -186.7 \\
\hline Winter wheat & -43.1 & -14.9 & -28.1 & -23.4 \\
\hline Total & -934.2 & -410.3 & -523.8 & -567.4 \\
\hline
\end{tabular}

Changes in subsidies and changes in the producer premiums may not sum to changes in total premiums due to rounding. 
Table A2. Predicted changes in total premiums, producer premiums, subsidies, and expected net returns due to three policy implications

\begin{tabular}{|c|c|c|c|c|}
\hline $\begin{array}{l}\text { Relative Risk } \\
\text { Aversion }=4.0\end{array}$ & $\begin{array}{c}\text { Change in } 2018 \text { Total } \\
\text { Premiums Collected } \\
\text { (Million \$) }\end{array}$ & $\begin{array}{c}\text { Change in } 2018 \text { Producer } \\
\text { Premiums Collected } \\
\text { (Million \$) }\end{array}$ & $\begin{array}{l}\text { Change in } 2018 \\
\text { Subsidies Paid } \\
\text { (Million \$) }\end{array}$ & $\begin{array}{c}\text { Change in } 2018 \\
\text { Expected Net Returns } \\
\text { (Million \$) }\end{array}$ \\
\hline & \multicolumn{4}{|c|}{ Scenario 1} \\
\hline Corn & -337.2 & -141.4 & -195.8 & -688.7 \\
\hline Soybeans & -310.8 & -139.2 & -171.5 & -534.8 \\
\hline Winter wheat & -16.11 & -6.0 & -10.1 & -17.4 \\
\hline \multirow[t]{2}{*}{ Total } & -664.1 & -286.7 & -377.4 & -1285.1 \\
\hline & \multicolumn{4}{|c|}{ Scenario 2} \\
\hline Corn & -818.5 & 395.1 & -1213.6 & -1779.5 \\
\hline Soybeans & -629.3 & 275.5 & -904.8 & -1254.8 \\
\hline Winter wheat & -107.9 & 59.2 & -167.1 & -211.2 \\
\hline \multirow[t]{2}{*}{ Total } & -1548.5 & 799.9 & -2348.5 & -3163.7 \\
\hline & \multicolumn{4}{|c|}{ Scenario 3} \\
\hline Corn & -195.5 & -28.8 & -166.7 & -176.4 \\
\hline Soybeans & -119.7 & -14.23 & -105.5 & -88.5 \\
\hline Winter wheat & -16.2 & -3.1 & -13.1 & -13.3 \\
\hline Total & -371.6 & -61.5 & -310.2 & -301.6 \\
\hline
\end{tabular}

Changes in subsidies and changes in the producer premiums may not sum to changes in total premiums due to rounding.

Table A3. Regional division and corresponding states

\begin{tabular}{|c|c|}
\hline Regional Division & States Included \\
\hline Corn Belt & Iowa, Illinois, Indiana, Missouri, Ohio \\
\hline Central Plains & Colorado, Kansas, Nebraska \\
\hline Lake States & Michigan, Minnesota, Wisconsin \\
\hline Northern Plains & Montana, North Dakota, South Dakota, Wyoming \\
\hline \multirow[t]{2}{*}{ Southeast } & Alabama, Georgia, Florida, Kentucky, \\
\hline & North Carolina, South Carolina, Tennessee, Virginia \\
\hline Southern Plains & New Mexico, Oklahoma, Texas \\
\hline \multirow[t]{5}{*}{ Other } & Arizona, Arkansas, Alaska, California, Connecticut, \\
\hline & Delaware, Hawaii, Idaho, Louisiana, Maine, \\
\hline & Maryland, Massachusetts, Mississippi, New Hampshire \\
\hline & New Jersey, Nevada, New York, Pennsylvania, Oregon, \\
\hline & Rhode Island, Utah, Vermont, Washington, West Virginia \\
\hline
\end{tabular}


Table A4. Predicted changes in total premiums, producer premiums, subsidies, and expected net returns due to three policy implications in Corn Belt and Central Pains regions

\begin{tabular}{|c|c|c|c|c|}
\hline $\begin{array}{l}\text { Relative Risk } \\
\text { Aversion }=2.5\end{array}$ & $\begin{array}{c}\text { Change in } 2018 \text { Total } \\
\text { Premiums Collected } \\
\text { (Million \$) }\end{array}$ & $\begin{array}{c}\text { Change in } 2018 \text { Producer } \\
\text { Premiums Collected } \\
\text { (Million \$) }\end{array}$ & $\begin{array}{l}\text { Change in } 2018 \\
\text { Subsidies Paid } \\
\text { (Million \$) }\end{array}$ & $\begin{array}{c}\text { Change in } 2018 \\
\text { Expected Net Returns } \\
\text { (Million \$) }\end{array}$ \\
\hline & \multicolumn{4}{|c|}{ Scenario 1} \\
\hline Corn & -337.5 & -121.1 & -216.5 & -570.7 \\
\hline Soybeans & -249.2 & -106.9 & -142.2 & -394.6 \\
\hline Winter wheat & -11.5 & -5.4 & -6.1 & -11.8 \\
\hline \multirow[t]{2}{*}{ Total } & -598.2 & -233.4 & -364.8 & -977.1 \\
\hline & \multicolumn{4}{|c|}{ Scenario 2} \\
\hline Corn & -463.6 & 245.7 & -709.3 & -900.8 \\
\hline Soybeans & -304.8 & 170.5 & -475.3 & -574.3 .0 \\
\hline Winter wheat & -47.0 & 14.3 & -61.3 & -72.6 \\
\hline \multirow[t]{2}{*}{ Total } & -815.4 & 430.5 & -1245.9 & -1547.7 \\
\hline & \multicolumn{4}{|c|}{ Scenario 3} \\
\hline Corn & -195.4 & -51.5 & -143.8 & -175.8 \\
\hline Soybeans & -96.7 & -19.5 & -77.2 & -66.2 \\
\hline Winter wheat & -11.6 & -3.0 & -8.6 & -8.6 \\
\hline Total & -303.7 & -74.0 & -229.6 & -250.6 \\
\hline
\end{tabular}

Changes in subsidies and changes in the producer premiums may not sum to changes in total premiums due to rounding.

Table A5. Predicted changes in total premiums, producer premiums, subsidies, and expected net returns due to three policy implications in Lake States region

\begin{tabular}{|c|c|c|c|c|}
\hline $\begin{array}{l}\text { Relative Risk } \\
\text { Aversion }=2.5\end{array}$ & $\begin{array}{c}\text { Change in } 2018 \text { Total } \\
\text { Premiums Collected } \\
\text { (Million \$) }\end{array}$ & $\begin{array}{c}\text { Change in } 2018 \text { Producer } \\
\text { Premiums Collected } \\
\text { (Million \$) }\end{array}$ & $\begin{array}{l}\text { Change in } 2018 \\
\text { Subsidies Paid } \\
\text { (Million \$) }\end{array}$ & $\begin{array}{c}\text { Change in } 2018 \\
\text { Expected Net Returns } \\
\text { (Million \$) }\end{array}$ \\
\hline & \multicolumn{4}{|c|}{ Scenario 1} \\
\hline Corn & -83.3 & -38.1 & -45.2 & -129.7 \\
\hline Soybeans & -71.4 & -37.5 & -33.9 & -103.5 \\
\hline Winter wheat & -1.1 & -0.5 & -0.6 & -0.8 \\
\hline \multirow[t]{2}{*}{ Total } & -155.8 & -76.1 & -79.7 & -234.0 \\
\hline & \multicolumn{4}{|c|}{ Scenario 2} \\
\hline Corn & -105.7 & 80.3 & -185.9 & -219.7 \\
\hline Soybeans & -98.4 & 64.5 & -162.8 & -191.3 \\
\hline Winter wheat & -4.0 & 0.5 & -4.5 & -4.8 \\
\hline \multirow[t]{2}{*}{ Total } & -207.9 & 145.3 & -353.2 & -415.8 \\
\hline & \multicolumn{4}{|c|}{ Scenario 3} \\
\hline Corn & -22.7 & -4.2 & -18.5 & -10.0 \\
\hline Soybeans & -16.7 & -1.8 & -14.9 & -7.8 \\
\hline Winter wheat & -0.7 & -0.2 & -0.6 & -0.3 \\
\hline Total & -40.2 & -6.2 & -34.0 & -18.1 \\
\hline
\end{tabular}

Changes in subsidies and changes in the producer premiums may not sum to changes in total premiums due to rounding. 
Table A6. Predicted changes in total premiums, producer premiums, subsidies, and expected net returns due to three policy implications in Northern Plains region

\begin{tabular}{|c|c|c|c|c|}
\hline $\begin{array}{l}\text { Relative Risk } \\
\text { Aversion }=2.5\end{array}$ & $\begin{array}{l}\text { Change in } 2018 \text { Total } \\
\text { Premiums Collected } \\
\text { (Million \$) }\end{array}$ & $\begin{array}{c}\text { Change in } 2018 \text { Producer } \\
\text { Premiums Collected } \\
\text { (Million \$) }\end{array}$ & $\begin{array}{l}\text { Change in } 2018 \\
\text { Subsidies Paid } \\
\text { (Million \$) }\end{array}$ & $\begin{array}{c}\text { Change in } 2018 \\
\text { Expected Net Returns } \\
\text { (Million \$) }\end{array}$ \\
\hline & \multicolumn{4}{|c|}{ Scenario 1} \\
\hline Corn & -65.3 & -28.5 & -36.8 & -72.1 \\
\hline Soybeans & -48.6 & -23.2 & -25.5 & -59.3 \\
\hline Winter wheat & -0.21 & -0.11 & -0.09 & -0.25 \\
\hline \multirow[t]{2}{*}{ Total } & -114.1 & -51.8 & -62.4 & -137.1 \\
\hline & \multicolumn{4}{|c|}{ Scenario 2} \\
\hline Corn & -182.9 & 81.7 & -264.7 & -339.4 \\
\hline Soybeans & -89.2 & 43.8 & -133.0 & -165.6 \\
\hline Winter wheat & -0.59 & 0.27 & -0.87 & -1.01 \\
\hline \multirow[t]{2}{*}{ Total } & -272.7 & 125.8 & -398.6 & -506.0 \\
\hline & \multicolumn{4}{|c|}{ Scenario 3} \\
\hline Corn & -43.5 & -7.1 & -36.4 & -43.0 \\
\hline Soybeans & -22.5 & -4.4 & -18.1 & -20.4 \\
\hline Winter wheat & -0.11 & -0.03 & -0.08 & -0.07 \\
\hline Total & -66.1 & -11.5 & -54.6 & -63.5 \\
\hline
\end{tabular}

Changes in subsidies and changes in the producer premiums may not sum to changes in total premiums due to rounding.

Table A7. Predicted changes in total premiums, producer premiums, subsidies, and expected net returns due to three policy implications in Southeast and Southern Plains regions

\begin{tabular}{|c|c|c|c|c|}
\hline $\begin{array}{l}\text { Relative Risk } \\
\text { Aversion }=2.5\end{array}$ & $\begin{array}{c}\text { Change in } 2018 \text { Total } \\
\text { Premiums Collected } \\
\text { (Million \$) }\end{array}$ & $\begin{array}{c}\text { Change in } 2018 \text { Producer } \\
\text { Premiums Collected } \\
\text { (Million \$) }\end{array}$ & $\begin{array}{l}\text { Change in } 2018 \\
\text { Subsidies Paid } \\
\text { (Million \$) }\end{array}$ & $\begin{array}{c}\text { Change in } 2018 \\
\text { Expected Net Returns } \\
\text { (Million \$) }\end{array}$ \\
\hline & \multicolumn{4}{|c|}{ Scenario 1} \\
\hline Corn & -32.9 & -16.2 & -16.8 & -46.7 \\
\hline Soybeans & -32.8 & -15.8 & -17.1 & -40.6 \\
\hline Winter wheat & -11.6 & -4.7 & -6.8 & -10.1 \\
\hline \multirow[t]{2}{*}{ Total } & -77.3 & -36.7 & -40.7 & -97.4 \\
\hline & \multicolumn{4}{|c|}{ Scenario 2} \\
\hline Corn & -82.7 & 47.5 & -130.1 & -164.4 \\
\hline Soybeans & -77.6 & 44.7 & -122.3 & -150.2 \\
\hline Winter wheat & -68.0 & 43.4 & -111.4 & -125.6 \\
\hline \multirow[t]{2}{*}{ Total } & -228.3 & 135.6 & -363.8 & -440.2 \\
\hline & \multicolumn{4}{|c|}{ Scenario 3} \\
\hline Corn & -21.6 & -4.3 & -17.3 & -19.5 \\
\hline Soybeans & -15.9 & -2.7 & -13.2 & -11.7 \\
\hline Winter wheat & -12.1 & -2.9 & -9.2 & -9.1 \\
\hline Total & -49.6 & -9.9 & -39.7 & -40.4 \\
\hline
\end{tabular}

Changes in subsidies and changes in the producer premiums may not sum to changes in total premiums due to rounding. 
Table A8. Predicted changes in total premiums, producer premiums, subsidies, and expected net returns due to three policy implications in Other regions

\begin{tabular}{|c|c|c|c|c|}
\hline $\begin{array}{l}\text { Relative Risk } \\
\text { Aversion }=2.5\end{array}$ & $\begin{array}{c}\text { Change in } 2018 \text { Total } \\
\text { Premiums Collected } \\
\text { (Million \$) }\end{array}$ & $\begin{array}{c}\text { Change in } 2018 \text { Producer } \\
\text { Premiums Collected } \\
\text { (Million \$) }\end{array}$ & $\begin{array}{l}\text { Change in } 2018 \\
\text { Subsidies Paid } \\
\text { (Million \$) }\end{array}$ & $\begin{array}{c}\text { Change in } 2018 \\
\text { Expected Net Returns } \\
\text { (Million \$) }\end{array}$ \\
\hline & \multicolumn{4}{|c|}{ Scenario 1} \\
\hline Corn & -14.2 & -7.1 & -7.1 & -19.8 \\
\hline Soybeans & -17.7 & -7.9 & -9.7 & -19.7 \\
\hline Winter wheat & -3.1 & -1.8 & -1.3 & -3.4 \\
\hline \multirow[t]{2}{*}{ Total } & -35.0 & -16.8 & -18.1 & -42.9 \\
\hline & \multicolumn{4}{|c|}{ Scenario 2} \\
\hline Corn & -32.8 & 19.3 & -52.2 & -63.6 \\
\hline Soybeans & -52.2 & 22.2 & -74.4 & -91.7 \\
\hline Winter wheat & -8.5 & 2.6 & -11.1 & -12.3 \\
\hline \multirow[t]{2}{*}{ Total } & -93.5 & 44.1 & -137.7 & -167.6 \\
\hline & \multicolumn{4}{|c|}{ Scenario 3} \\
\hline Corn & -7.6 & -1.2 & -6.5 & -5.4 \\
\hline Soybeans & -8.1 & -1.1 & -6.9 & -5.7 \\
\hline Winter wheat & -1.2 & -0.3 & -0.8 & -0.7 \\
\hline Total & -16.9 & -2.6 & -14.2 & -11.8 \\
\hline
\end{tabular}

Changes in subsidies and changes in the producer premiums may not sum to changes in total premiums due to rounding. 
Table A9. Predicted changes in total premiums, producer premiums, subsidies, and expected net returns due to three policy implications when compared to the base for 2017

\begin{tabular}{|c|c|c|c|c|}
\hline $\begin{array}{l}\text { Relative risk } \\
\text { aversion }=2.5\end{array}$ & $\begin{array}{c}\text { Change in } 2017 \text { Total } \\
\text { Premiums Collected } \\
\text { (Million\$) }\end{array}$ & $\begin{array}{c}\text { Change in } 2017 \text { Producer } \\
\text { Premiums Collected } \\
\text { (Million \$) }\end{array}$ & $\begin{array}{l}\text { Change in } 2017 \\
\text { Subsidies Paid } \\
\text { (Million \$) }\end{array}$ & $\begin{array}{c}\text { Change in } 2017 \\
\text { Expected Net Returns } \\
\text { (Million \$) }\end{array}$ \\
\hline & \multicolumn{4}{|c|}{ Scenario 1} \\
\hline Corn & -537.7 & -221.6 & -316.1 & -853.8 \\
\hline Soybeans & -487.5 & -205.8 & -281.6 & -590.9 \\
\hline Winter wheat & -26.9 & -14.3 & -12.6 & -28.9 \\
\hline \multirow[t]{2}{*}{ Total } & -1052.1 & -441.7 & -610.3 & -1473.6 \\
\hline & \multicolumn{4}{|c|}{ Scenario 2} \\
\hline Corn & -972.6 & 480.6 & -1453.2 & -1809.8 \\
\hline Soybeans & -796.8 & 318.5 & -1115.3 & -1264.5 \\
\hline Winter wheat & -125.9 & 64.0 & -189.9 & -210.3 \\
\hline \multirow[t]{2}{*}{ Total } & -1895.3 & 863.1 & -2758.4 & -3284.6 \\
\hline & \multicolumn{4}{|c|}{ Scenario 3} \\
\hline Corn & -353.6 & -73.0 & -280.6 & -294.0 \\
\hline Soybeans & -218.1 & -48.2 & -169.9 & -148.4 \\
\hline Winter wheat & -30.1 & -7.8 & -22.2 & -17.5 \\
\hline Total & -601.8 & -129.0 & -472.7 & -459.9 \\
\hline
\end{tabular}

Changes in subsidies and changes in the producer premiums may not sum to changes in total premiums due to rounding.

Cite this article: Maisashvili A, Bryant HL, and Jones JPH (2020). Implications of Alternative Crop Insurance Subsidies. Journal of Agricultural and Applied Economics 52, 240-263. https://doi.org/10.1017/aae.2019.46 